\title{
In vitro activity of neem oil [Azadirachta indica A. Juss (Meliaceae)] on Aspergillus flavus growth, sporulation, viability of spores, morphology and Aflatoxins $B_{1}$ and $B_{2}$ production
}

\author{
Christiane L. da Costa ${ }^{1}$, Marcia R. F. Geraldo ${ }^{2}$, Carla C. Arrotéia ${ }^{1}$, Carlos Kemmelmeier ${ }^{1}$ \\ ${ }^{1}$ Department of Biochemistry, Universidade Estadual de Maringá. Avenida Colombo, Maringá, Brazil; \\ ${ }^{2}$ Universidade Tecnológica Federal do Paraná, Campo Mourão, Brazil. \\ Email: christiane@ffalm.br; mperdoncini@ibest.com.br; ccarroteia@uem.br; ckemmelmeier@uem.br
}

Received 29 June2010; revised 15 July2010; accepted 25 July 2010.

\begin{abstract}
The effectiveness of neem (Azadiracta indica) oil on the growth, morphology, sporulation, viability of spores, aflatoxin $B_{1}$ and $B_{2}$ production by $A$. flavus on Yeast Extract-Sucrose medium was determined. Neem oil inhibited the fungal growth (i.e. mycelia dry weight, diameter of colony and growth rate) on solid media at concentrations from 0.5 to $5.0 \% \mathrm{v} / \mathrm{v}$, although it significantly increased sporulation in the same conditions. Spores obtained from cultures grown without neem oil reduced germination when incubated in a neem-oil supplemented medium. Colonies grown on solid media and in submerged cultures in the presence of neem oil exhibited morphological alterations, including granular cytoplasm, atypical hyphae branching pattern, abnormal and undifferentiated conidiophores. High Performance Liquid Chromatography was used to measure aflatoxins. In submerged cultures, neem oil at concentrations from 0.5 to $4.0 \% \mathrm{v} / \mathrm{v}$ caused approximately $95 \%$ inhibition in Aflatoxin $B_{1}$ and $B_{2}$. On other hand, these conditions failed to suppress fungal growth. Current research emphasized that neem oil was not fungistatic or fungicidal, but exhibited anti-aflatoxigenic activity.
\end{abstract}

Keywords: Azadirachta indica; Aspergillus flavus; Neem oil; Aflatoxins

\section{INTRODUCTION}

Aflatoxins are polyketide secondary metabolites produced by toxigenic strains of Aspergillus section Flavi group: Aspergillus flavus, A. parasiticus, A. nomius, A. tamarii and A. bombysis. A. flavus is the main source of aflatoxins, the most important mycotoxins in the world's food supplies, due to its mutagenic, carcinogenic and teratogenic properties. Aflatoxin $\mathrm{B}_{1}\left(\mathrm{AFB}_{1}\right)$ and $\mathrm{B}_{2}$ $\left(\mathrm{AFB}_{2}\right)$ are the most important among 18 different types. World-wide occurrence of Aspergillus flavus and aflatoxins in a great variety of food crops has triggered much research with regard to its causes, progress and prevention $[1,2]$.

There has recently been an extensive search for alternatives to fungicides that would provide satisfactory aflatoxin control with low impact on the environment and on human health [3]. Previous studies have shown that biosynthesis of aflatoxins may be inhibited by neem extracts. Azadirachta indica (Meliaceae), commonly know as neem, is an evergreen tree, cultivated in arid regions of Africa and the Asian subcontinent. Every part of the neem tree has been used in traditional folk medicine in India as a household remedy against various human ailments and also as a pesticide. Several active substances from different parts of the tree have an unusual effectiveness on a wide spectrum of pests, including fungi. Due to its efficacy, biodegradability and minimum side effects, azadirachtin, a tetranortriterpenoid obtained from neem seeds, has emerged as a natural biopesticide $[4,5]$.

Previous studies have shown that biosynthesis of aflatoxins may be inhibited by neem extracts. Bhatnagar and co-workers have demonstrated that blended neem leaf extracts inhibited aflatoxin production by A. parasiticus and $A$. flavus, but they failed to affect fungal growth $[6,7]$. Further, neem leaves contain specific volatile compounds with fungicidal properties. This complex mixture of volatiles affected both fungal growth and aflatoxin production in A. parasiticus [8]. Other studies on A. parasiticus have shown that aflatoxin inhibition by 
neem leaf extract is associated with changes in the activities of cytosolic enzymes [9] and also with morphological alterations in the mycelia [10].

Data on fungal growth and mycotoxin production in the presence of neem extracts, besides those on aflatoxins, are scanty, but in vitro studies with neem extracts showed inhibition of the polyketide mycotoxins, namely, patulin [11,12], citrinin [13], sterigmatocystin [14], but no inhibitory effect on penicillic acid [14], fumonisin [15] and ochratoxin A production [16].

The main chemical fractions of neem oil with antifungal activities are a mixture of triterpenoidal and tetranortriterpenoid compounds. Azadirachtin, 6-deacetylnimbin, azadiradione, nimbin, salannim and epoxyazadiradione were the major compounds obtained from chemical fractions of neem oil. Although when tested alone they did not have any appreciable activity, they showed antifungal activity when mixed and indicated possible additive/synergistic effects [17].

There is scanty information available in the literature on the effect of neem oil on growth, sporulation level and aflatoxins production by $A$. flavus in submerged cultures. Thus, current study determines the effectiveness of neem oil on the growth, morphology, sporulation, viability of spores and $\mathrm{AFB}_{1}$ and $\mathrm{AFB}_{2}$ production by $A$. flavus on a semi-synthetic medium.

\section{MATERIALS AND METHODS}

\subsection{Microorganism}

The aflatoxigenic strain Aspergillus flavus 42 was isolated from peanut seeds and identified by physiological and morphological tests [1] at the Laboratory of Chemistry and Physiology of Microorganisms (Biochemistry Department, State University of Maringá, Maringá. PR Brazil). The isolate was stored in silica [18] and cultured on Potato Dextrose Agar (PDA) for seven days, at $25^{\circ} \mathrm{C}$, in the dark [19], for the production of conidia. The conidia suspension used as inoculum was prepared by washing the cultures in sterile Tween $80(0.01 \%)$ solution and placed in a Neubauer chamber for conidia counting.

\subsection{Neem Seed Oil (NO)}

Oil from neem seeds (NO) used in organic agriculture (Bioneem ${ }^{\circledR}$ Co., Brazil) was obtained by cold pressing, which is the best method to obtain quality neem oil.

\subsection{Culture Conditions for Aflatoxin Production in Submerged Cultures}

The semi-synthetic YES (Yeast Extract Sucrose) medium, conventionally employed for testing aflatoxin production [20], was used as culture medium. Flasks containing $50 \mathrm{~mL}$ of autoclaved YES liquid medium, in the absence (control) and presence of NO (treatments) were inoculated with $1.0 \mathrm{~mL}$ of conidia suspension $\left(10^{6}\right.$ conidia $\left.\mathrm{mL}^{-1}\right)$ and incubated in a static condition for 7 days, in the dark, at $25^{\circ} \mathrm{C}$. Emulsified $\mathrm{NO}$ was evaluated at $0.25,0.5,1.0$ and $4.0 \%(\mathrm{v} / \mathrm{v})$. Neem oil is frequently used at $0.5 \%$ in aqueous solutions to control pests on crops. Flasks in each treatment were prepared in five replicates. Two replicates were used in the analysis of aflatoxins and the remaining three processed for morphological studies, as described in the "Morphological studies" section.

\subsection{Extraction and Quantification of Aflatoxins}

After cultures have been filtered at the end of the growth period, an aliquot from the culture $(20 \mathrm{~mL})$ was extracted twice, with chloroform $(30 \mathrm{~mL})$, at each period. The combined chloroform extract was filtered by anhydrous sodium sulfate to remove residual water, evaporated till dryness and then re-suspended in $1 \mathrm{~mL}$ chloroform [21]. Fresh mycelia obtained from each flask were washed in water, dried at $85^{\circ} \mathrm{C}$ for $24 \mathrm{hrs}$ and weighed. Dry weight of the fungus was determined as an index of fungal growth [6]. Aflatoxins were quantitatively determined by HPLC, following the methodology proposed by Passone et al. [22]. The limit of detection of the analytical method was $1 \mathrm{ng} / \mathrm{g}$. and the recovery coefficient was $85.5 \%$. Aflatoxins are expressed in terms of ppm ( $\mu \mathrm{g}$ aflatoxin/g mycelial growth weight). Analyses were performed by LAMIC (Laboratório de Análises Micotoxicológicas, Santa Maria, RS Brazil) and results extracted from the 01/2008 analysis.

\subsection{Mycelial Growth and Sporulation Measurement}

The effect of NO on the growth and sporulation of $A$. flavus in solid media was determined by growing the fungus on a YES agar in the absence (control) and presence (treatments) of different concentrations of NO: 0.25 , $0.5,1.0,2.0,3.0,4.0$ and $5.0 \%(\mathrm{v} / \mathrm{v})$. The solid media were prepared by adding $2 \%$ of agar in liquid media, autoclaved, transferred to $95 \mathrm{~mm}$-Petri dishes, solidified and inoculated with a single culture at the center of the plate. To this purpose, fungi had been previously cultured in PDA in Petri dishes, according to the streaking technique [1] for producing isolated colonies. A. flavus was subsequently incubated at $25^{\circ} \mathrm{C}$ for 7 days, in the dark. All plates of each treatment were prepared in six replicates. Whereas three plates were used to determine the growth, the other plates were used for sporulation measurement. Growth was recorded in terms of diameter of colony and dry weight. The advantage of the first method was that sequential records might be obtained from each colony, although only lateral but not aerial 
growth was measured [23]. The diameter of fungal colonies was measured daily in two directions at $90^{\circ}$ from each other to obtain the mean diameter for each colony [24]. Each plate's diameter increase was plotted as a function of incubation time whereas radial growth rate was obtained from the slope by regression of the linear growth phase [25]. So that the mycelium dry weight after the growth period could be evaluated, each Petri plate was placed in a microwave oven during 20 s to melt the medium. The mycelium was then separated from the medium by filtration and washed in distilled water, at an approximate temperature of $60^{\circ} \mathrm{C}$. This preparation was placed in an oven at $85^{\circ} \mathrm{C}$ until weight constant [26].

Procedures for sporulation measurement followed Gusmán-de-Peña and Ruiz-Herrera [27] with modifications. A solid medium has been used in this study since the fungus sporulation is inconsistent in liquid media [28]. Three agar discs ( $8 \mathrm{~mm}$ diameter) were aseptically removed from central, intermediate and peripheral zones of each replicate plate using a cork borer, transferred to flasks containing a sterile $0.1 \%$ Tween 80 solution (10 $\mathrm{mL}$ ) and stirred for two minutes with a vortex to release the spores. After mycelium sedimentation, the supernatant containing the spores was recovered and estimated by a Neubauer counting chamber. The sporulation data were recorded in spores $/ \mathrm{cm}^{2}$ of colony.

\subsection{Germination}

Two experiments were performed to evaluate the effects of $\mathrm{NO}$ on viability of spores:

Experiment 1: Viability of spores grown in the presence NO in a NO-less medium.

Suspensions prepared as in the previous section were diluted to obtain approximately 600 spores $/ \mathrm{mL}$. $1 \mathrm{~mL}$ of each suspension was inoculated on sterile strips of dialysis membrane $(1 \mathrm{~cm} \times 1 \mathrm{~cm})$ placed on the surface of Petri plates containing YES agar without NO and incubated at $25^{\circ} \mathrm{C}$ for $10 \mathrm{hrs}$. The membranes were placed on a slide, stained with lacto-phenol cotton blue and examined under the microscope. A germinated spore was considered as such when its germ tube was longer than half the diameter of the spore. Further, 300 spores were randomly counted on each slide, giving a total of 900 spores per treatment. Germination was reported as a percentage of spore population and compared with the corresponding control. Three slides were sampled per treatment. The analysis of germ-tube morphology in each slide was performed for observation by biological optic photomicroscope [29].

Experiment 2: Viability of spores grown in the absence of NO in a NO-supplemented medium. Spore suspension obtained from cultures grown on the agar YES without NO were prepared and inoculated in Petri plates con- taining YES agar with different concentrations of NO $(0.25 ; 0.5 ; 1.0 ; 2.0 ; 3.0 ; 4.0$ and $5.0 \mathrm{v} / \mathrm{v})$, incubated and analyzed, following the methodology previously described.

\subsection{Morphological Studies}

The same plates used in the sporulation test were employed in the morphological studies. Samples of mycelial growth were taken at the central, intermediate, peripheral zones of the colonies. They were then stained with lactophenol cotton blue or lactofuchsin, and examined under the Zeiss Axiophot light microscope. Slides from germination test were analyzed to evaluate the polarity of germ tubes, although no quantitative tests were performed to assess this parameter.

\section{RESULTS}

\subsection{Effect of NO on A. flavus Growth, Sporulation and Viability of Spores in Solid Media}

Data in Table 1 showed that diameter, dry weight, growth rate, were suppressed by $\mathrm{NO}$ and that this reduction effect was more efficient in concentrations above $0.5 \%$. However, it significantly increased the sporulation in the same concentrations.

Results of experiments to find the effect of NO on viability of spores showed a $1.0 \%$ decrease in the germination percentage of spores produced by colonies in the presence of NO. Furthermore, germination was significantly reduced when spores from control cultures were incubated in a NO-supplemented medium at concentrations above $0.5 \%$ (Table 1 ).

\subsection{Effect of NO on morphology of A. flavus}

Besides inhibited growth, colonies grown on solid media in the presence of $\mathrm{NO}$ at all concentrations exhibited morphological alterations when compared to control (Figure 1(a) and 1(c)). Analysis showed that treated hyphae (Figure 1(b)) present granular cytoplasm containing large number of vesicular structures. This feature was detected in all segments from the center to the peripheral zones. Furthermore, the hyphae presented variation in the typical branching pattern (Figure 1(d)), with more than two tips per branching point. Hyphae diameter increased too, although specific measures were not undertaken. Treated hyphae obtained from submerged cultures also showed granular cytoplasm and the same branching pattern. Morphological alterations have not varied in the presence of different concentrations employed in this study. Although spores normally produced a single germ-tube (Figure 1(e)), some spores revealed bipolar germination in NO-supplemented media (Figure 1(f)). In spite of the fact that control hyphae showed typical 
Table 1. Effect of NO on A. flavus growth, sporulation and viability of spores in solid media.

\begin{tabular}{|c|c|c|c|c|c|c|}
\hline $\begin{array}{c}\text { NO } \\
(\% \mathrm{v} / \mathrm{v})\end{array}$ & $\begin{array}{l}\text { Mycelial dry } \\
\text { weight (g) }\end{array}$ & Diameter (cm) & $\begin{array}{l}\text { Growth rate } \\
\quad(\mathbf{c m} / \mathbf{h})\end{array}$ & $\begin{array}{c}\text { Sporulation } \\
\left(10^{6} \text { spores } / \mathrm{cm}^{2}\right)\end{array}$ & $\begin{array}{c}\text { Germination } \\
\text { Experiment } 1 \\
(\%)^{*}\end{array}$ & $\begin{array}{c}\text { Germination } \\
\text { Experiment } 2 \\
\mathbf{( \% )}^{* * *}\end{array}$ \\
\hline $\begin{array}{c}0 \\
\text { (Control) }\end{array}$ & $\begin{array}{l}0.44^{\mathrm{a}} \\
(0.02)\end{array}$ & $\begin{array}{l}7.90^{\mathrm{a}} \\
(0,1)\end{array}$ & $\begin{array}{c}0.044^{\mathrm{a}} \\
\left(3.0 \times 10^{-4}\right)\end{array}$ & $\begin{array}{l}1.41^{\mathrm{c}} \\
(0.15)\end{array}$ & $\begin{array}{c}95.76^{\mathrm{ab}} \\
(1.01)\end{array}$ & $\begin{array}{l}95.76^{\mathrm{a}} \\
(1.01)\end{array}$ \\
\hline 0.25 & $\begin{array}{l}0.32^{\mathrm{b}} \\
(0.04)\end{array}$ & $\begin{array}{l}7.20^{\mathrm{b}} \\
(0,1)\end{array}$ & $\begin{array}{c}0.043^{\mathrm{b}} \\
\left(8.6 \times 10^{-5}\right)\end{array}$ & $\begin{array}{l}4.24^{\mathrm{c}} \\
(0.26)\end{array}$ & $\begin{array}{l}98.31^{\mathrm{a}} \\
(1.11)\end{array}$ & $\begin{array}{l}89.08^{\mathrm{a}} \\
(0.80)\end{array}$ \\
\hline 0.5 & $\begin{array}{l}0.42^{\mathrm{a}} \\
(0.02)\end{array}$ & $\begin{array}{c}7.93^{\mathrm{a}} \\
(0,057)\end{array}$ & $\begin{array}{c}0.045^{\mathrm{a}} \\
\left(1.5 \times 10^{-4}\right)\end{array}$ & $\begin{array}{l}24.32^{\mathrm{b}} \\
(2.02)\end{array}$ & $\begin{array}{l}96.25^{\mathrm{ab}} \\
(0.52)\end{array}$ & $\begin{array}{l}85.42^{\mathrm{b}} \\
(3.85)\end{array}$ \\
\hline 1.0 & $\begin{array}{l}0.17^{\mathrm{c}} \\
(0.02)\end{array}$ & $\begin{array}{l}3.30^{\mathrm{c}} \\
(0,1)\end{array}$ & $\begin{array}{c}0.018^{\mathrm{c}} \\
\left(3.4 \times 10^{-4}\right)\end{array}$ & $\begin{array}{l}42.46^{\mathrm{a}} \\
(3.98)\end{array}$ & $\begin{array}{l}91.04^{\mathrm{c}} \\
(2.91)\end{array}$ & $\begin{array}{l}87.21^{\mathrm{b}} \\
(2.15)\end{array}$ \\
\hline 2.0 & $\begin{array}{l}0.16^{\mathrm{c}} \\
(0.03)\end{array}$ & $\begin{array}{l}3.00^{\mathrm{d}} \\
(0,1)\end{array}$ & $\begin{array}{c}0.017^{\mathrm{d}} \\
\left(5.6 \times 10^{-4}\right)\end{array}$ & $\begin{array}{l}41.57^{\mathrm{a}} \\
(4.26)\end{array}$ & $\begin{array}{l}94.04^{\mathrm{bc}} \\
(1.51)\end{array}$ & $\begin{array}{l}85.55^{\mathrm{b}} \\
(3.37)\end{array}$ \\
\hline 3.0 & $\begin{array}{l}0.14^{\mathrm{c}} \\
(0.01)\end{array}$ & $\begin{array}{l}2.73^{\mathrm{e}} \\
(0,05)\end{array}$ & $\begin{array}{c}0.016^{\mathrm{e}} \\
\left(2.5 \times 10^{-4}\right)\end{array}$ & $\begin{array}{l}49.53^{\mathrm{a}} \\
(3.86)\end{array}$ & $\begin{array}{l}95.94^{\mathrm{ab}} \\
(0.78)\end{array}$ & $\begin{array}{l}86.49^{b} \\
(2.52)\end{array}$ \\
\hline 4.0 & $\begin{array}{l}0.14^{\mathrm{c}} \\
(0.02)\end{array}$ & $\begin{array}{l}2.83^{\mathrm{de}} \\
(0,05)\end{array}$ & $\begin{array}{c}0.015^{\mathrm{f}} \\
\left(3.2 \times 10^{-4}\right)\end{array}$ & $\begin{array}{l}46.44^{\mathrm{a}} \\
(3.71)\end{array}$ & $\begin{array}{l}95.94^{\mathrm{ab}} \\
(0.40)\end{array}$ & $\begin{array}{l}81.82^{\mathrm{b}} \\
(2.99)\end{array}$ \\
\hline 5.0 & $\begin{array}{c}0.17^{\mathrm{c}} \\
(0.01)\end{array}$ & $\begin{array}{l}2.80^{\text {de }} \\
(0,00)\end{array}$ & $\begin{array}{c}0.018^{\mathrm{c}} \\
\left(2.5 \times 10^{-4}\right)\end{array}$ & $\begin{array}{l}49.89^{\mathrm{a}} \\
(5.36)\end{array}$ & $\begin{array}{l}93.52^{\mathrm{bc}} \\
(1.38)\end{array}$ & $\begin{array}{l}84.27^{\mathrm{b}} \\
(3.31)\end{array}$ \\
\hline
\end{tabular}

Note. Values (mean from three replicates) in the same column followed by a similar letter are not significantly different, according to Tukey HSD test (p $<0.05$ ). Values between parentheses are standard deviation of replicates. *Viability of spores grown in the presence of Neem oil in a medium without this compound. **Viability of spores grown in the absence of Neem oil in a medium supplemented with this compound.

conidiophores (Figure $\mathbf{1}(\mathrm{g})$ ), dichotomous branching and homogenous cytoplasm, vesicles were detected in the apical regions. The above morphological characteristics were consistent with those described in literature $[1,30]$. Abnormal conidiophores were recorded in colonies on solid media in the presence of NO at concentrations above $1.0 \%$. Secondary conidiophores (Figure 1(h)) formed from globose vesicles and undifferentiated conidiophores were detected (Figure 1(i) and 1(j)).

\subsection{Effect of NO on Aflatoxins Production by $A$. flavus in Submerged Cultures}

As shown in Table 2, the production of $\mathrm{AFB}_{1}$ and $\mathrm{AFB}_{2}$ was inhibited by $\mathrm{NO}$, which, at concentrations above $0.5 \%$, caused approximately $95 \%$ inhibition in $\mathrm{AFB}_{1}$ and $\mathrm{AFB}_{2}$ production. Presence of NO $4.0 \%$ in the fungal growth medium was sufficient to obtain total inhibition of $\mathrm{AFB}_{2}$ production. Results (Table 2) demonstrate that NO does not depress fungal growth in submerged culture.

\section{DISCUSSION}

Several authors have described the inhibitory effect of neem extracts on aflatoxin production. Bankole [31] showed that the NO at 1000 ppm was able to block the $\mathrm{AFB}_{1}$ synthesis by Aspergillus flavus inoculated in maize grain. Similar results were found by Zeringue and Bhatnagar [7], where the application of aqueous extract from neem leaves in cotton balls infected with Aspergillus flavus, was able to inhibit up to $98 \%$ the $\mathrm{AFB}_{1}$ production, without reducing the mycelial growth. The addition of the aqueous neem leaf extract in submerged cultures of Aspergillus parasiticus over 5.0\% concentrations caused inhibition of over $90 \%$ in $\mathrm{AFB}_{1}$ production, but did not affect mycelial growth [6,32]. The above authors have suggested that the inhibitory components in these extracts are non-volatile and influence the regulation of secondary metabolic pathway involved in aflatoxin biosynthesis. The results of present study corroborates this previous finding, show inhibition of approximately $95 \%$ in the $\mathrm{AFB}_{1}$ and $\mathrm{AFB}_{2}$ production when 0.5 , 1.0 and $4.0 \%$ of $\mathrm{NO}$ were added in submerged cultures of Aspergillus flavus. However, there was an increase in mycelial growth. The difference in the efficacy of anti-aflatoxigenic activity of neem extracts may be attributed to their composition and to different fungus metabolism. Although different commercial formulations of $\mathrm{NO}$ are available, the recommended aspersion of aqueous solution $5.0 \%$ in crops seems to be promising as a protector during storage [3]. It is not yet known which substance has anti-aflatoxigenic activity. Azadirachtin, a tetranortriterpenoid, is the most important active component in the neem tree and its highest concentration is found in seeds. When the neem tree was screened for antioxidant property, it was found that azadirachtin has a strong antioxidant activity [33]. A common feature of 


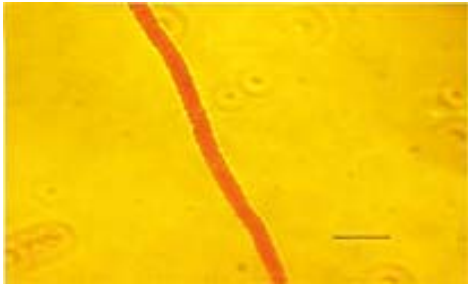

(a)

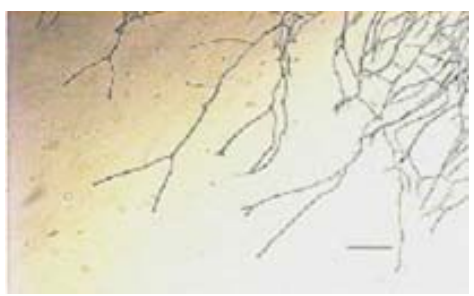

(c)

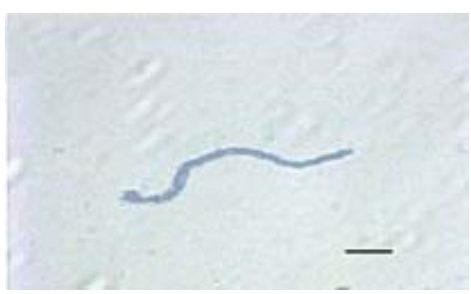

(e)

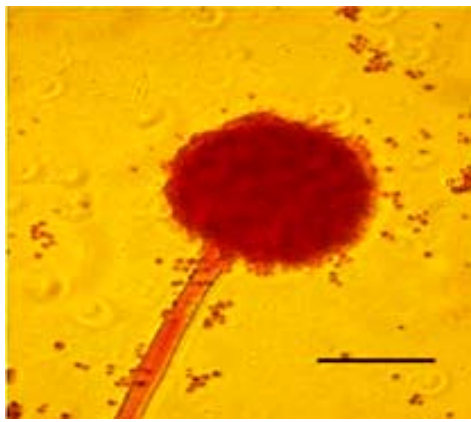

(g)

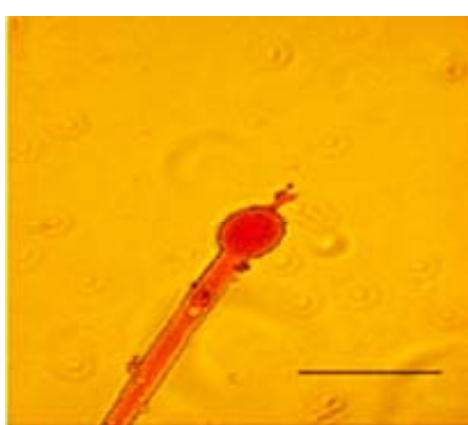

(i)

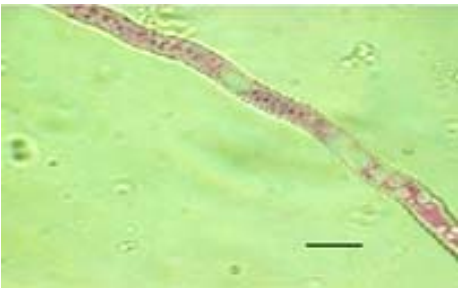

(b)

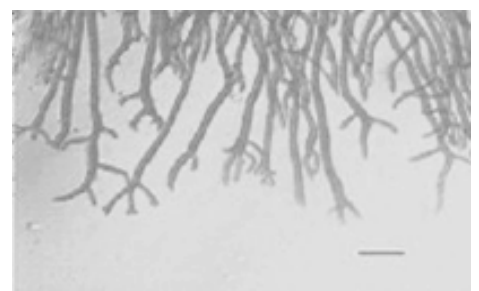

(d)

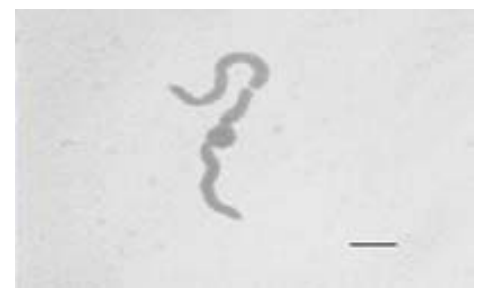

(f)

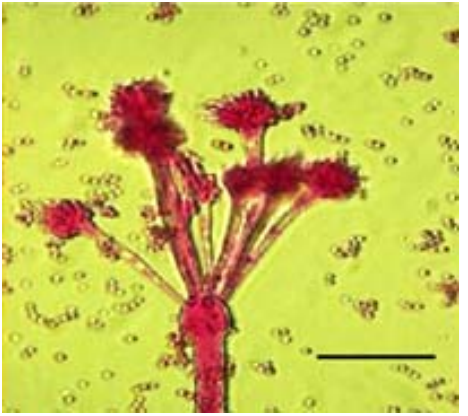

(h)

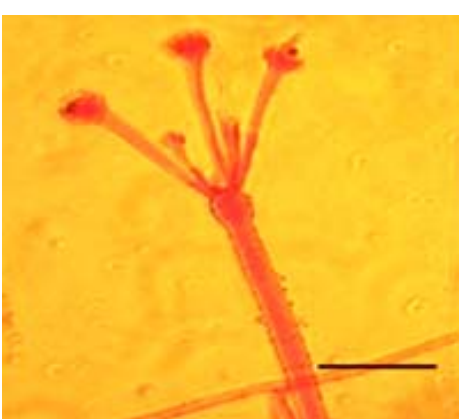

(j)

Figure 1. Effects of NO on the morphology of A. flavus in solid media: (a) Control hyphae; (b) and in the presence of 5\% NO. Scale bars represent $10 \mu \mathrm{m}$. (c) Control mycelia, (d) and in the presence of 5\% NO. (e) Spore obtained from control culture grown in the absence of NO, (f) and in the presence of $5 \% \mathrm{NO}$ after $10 \mathrm{hrs}$ of incubation at $25^{\circ} \mathrm{C}$. (g) Control and treated conidiophores $(\mathrm{h}, \mathrm{i}, \mathrm{j})$ grown in the presence of 5, 3 and $2 \% \mathrm{NO}$, respectively. Scale bars represent $40 \mu \mathrm{m}$. 
Table 2. Effects of NO on growth and aflatoxins production by A. flavus in submerged culture.

\begin{tabular}{|c|c|c|c|c|c|}
\hline $\begin{array}{c}\text { NO } \\
(\% \mathrm{v} / \mathrm{v})\end{array}$ & $\begin{array}{l}\text { Mycelial dry weight } \\
(\mathrm{g} / 50 \mathrm{~mL})\end{array}$ & $\begin{array}{c}\mathrm{AFB}_{1} \\
(\mu \mathrm{g} / \mathrm{g} \text { dry weight) }\end{array}$ & $\%$ of $\mathrm{AFB}_{1}$ inhibition & $\begin{array}{c}\mathrm{AFB}_{2} \\
(\mu \mathrm{g} / \mathrm{g} \text { dry weight) }\end{array}$ & $\%$ of $\mathrm{AFB}_{2}$ inhibition \\
\hline $\begin{array}{c}0 \\
\text { (Control) }\end{array}$ & $\begin{array}{c}0.80^{\mathrm{b}} \\
(0.04)\end{array}$ & $\begin{array}{l}12195.43^{\mathrm{a}} \\
(1299.43)\end{array}$ & 0 & $\begin{array}{l}891.60^{\mathrm{a}} \\
(156.77)\end{array}$ & 0 \\
\hline 0.25 & $\begin{array}{l}0.83^{\mathrm{b}} \\
(0.02)\end{array}$ & $\begin{array}{l}4888.13^{\mathrm{b}} \\
(527.80)\end{array}$ & 59.92 & $\begin{array}{l}104.20^{\mathrm{b}} \\
(29.00)\end{array}$ & 88.34 \\
\hline 0.5 & $\begin{array}{l}0.94^{\mathrm{b}} \\
(0.05)\end{array}$ & $\begin{array}{l}581.96^{\mathrm{c}} \\
(129.84)\end{array}$ & 95.23 & $\begin{array}{l}31.50^{\mathrm{b}} \\
(21.30)\end{array}$ & 94.17 \\
\hline 1.0 & $\begin{array}{l}0.94^{\mathrm{b}} \\
(0.04)\end{array}$ & $\begin{array}{l}622.90^{\mathrm{c}} \\
(137.69)\end{array}$ & 94.90 & $\begin{array}{l}48.90^{\mathrm{b}} \\
(10.17)\end{array}$ & 94.96 \\
\hline 4.0 & $\begin{array}{l}1.13^{\mathrm{a}} \\
(0.14)\end{array}$ & $\begin{array}{l}523.36^{\mathrm{C}} \\
(35.67)\end{array}$ & 95.71 & $\mathrm{ND}^{*}$ & - \\
\hline
\end{tabular}

Note. Values (mean from three replicates) in the same column followed by a similar letter are not significantly different, according to Tukey HSD test (p $<0.05$ ). Values between parentheses are standard deviation of replicates. * Not detected.

many aflatoxin inhibitors is their antioxidant activity [3], although the modes of action of most inhibitors, including neem, are still poorly understood. In spite of the fact that we have not investigated the complex area on the mode of neem's function on the Aspergillus flavus metabolism, earlier reports from our laboratory have demonstrate an inhibitory effect on in vitro polyketide mycotoxins production, such as sterigmatocystin (second-to-last intermediate item in aflatoxin pathway), patulin and citrinin by Aspergillus nidulans, Penicillium expansum and P. citrinum [11-14], respectively. Thus, neem activity may be extant in the biosynthetic polyketide pathway, including oxidation reactions. In solid media, NO in concentrations above $0.5 \%$ had inhibitory effect on diameter, dry weight and growth rate, but the spore count (i.e. sporulation) in all the treated groups remained high. Gowda and co-workers [34] showed a similar result when they isolated A. parasiticus in solid media. The presence of oil in the solid media caused inhibition in spore germination. Similarly, Suberu [35] reported inhibition of spore germination in A. flavus by lichen extracts. On other hand, the viability of spores obtained from cultures in the presence of $\mathrm{NO}$ in a NO-less medium is not affected (Table 2), except at concentration $1.0 \%$.

According to Razzaghi-Abyaneh et al. [10], the suppressive effects of neem leaf and seed extract on aflatoxin biosynthesis are associated with morphological alterations in the mycelium, such as vacuolation of cytoplasm and attenuation of cell wall. This fact suggests that probably the integrity of the cell barriers, particularly that of the cell wall, is crucial in the regulation of aflatoxin production and excretion. Our investigations show that treated hyphae, obtained from solid media and submerged cultures, present granular cytoplasm with many vesicular structures and variation in the typical branching pattern. The atypical branching pattern and the spores that showed bipolar germination suggest that NO probably affected hyphal polarity maintenance (the continued deposition of wall material at the extending tip). Abnormal and undifferentiated conidiophores were recorded in colonies on solid media in the presence of $\mathrm{NO}$ at concentrations above $1.0 \%$. The ketone $\beta$-ionone is an antiaflatoxigenic agent and presented similar effects on the morphology of the asexual reproductive structures of A. flavus. Aflatoxin synthesis may be positively correlated with the asexual reproductive process [36]. In addition, other authors demonstrated that the loss of aflatoxigenic capacity in the Aspergillus mutant form is correlated with the aberrant morphology of conidiophores [37]. The present study emphasized that NO was not fungistatic or fungicidal, but exhibited anti-aflatoxigenic activity.

Neem aqueous and oily extracts, in a similar range of concentrations such as those used in the present study, showed inhibitory effects when tested against some polyketide mycotoxins [11-14], albeit ineffective to penicillic acid [14], and ochratoxin A [16]. Thus, the above data and those obtained in current research reinforce the fact that the use of NO could be implemented as part of a sustainable integrated pest management strategy for mycotoxin control and plant diseases.

\section{ACKNOWLEDGEMENTS}

We would like to thank Dr. Thomas Bonnici for the grammatical review of the manuscript and to the National Council of Scientific and Technological Development-CNPq for its support in this research.

\section{REFERENCES}

[1] Pitt, J.I. and Hocking, A.D. (1977) Fungi and Food Spoilage. 2nd Edition, Blackie Academic \& Professional, 
London, United Kingdom.

[2] Hedayati, M.T, Pasqualotto, A.C, Warn, P.A, Bowyer, P. and Denning, D.W. (2007) Aspergillus flavus: Human pathogen, allergen and mycotoxin producer. Microbiology, 153, 1677-1692.

[3] Holmes, R.A., Boston, R.S. and Payne, G.A. (2008) Diverse inhibitors of aflatoxin biosynthesis. Applied Microbiology and Biotechnology, 78(4), 559-572.

[4] Martinez, S.S. (2002) O Nim-Azadirachta indica. Natureza, Usos Múltiplos, Produção. In: Martinez, S.S. Ed., IAPAR, Londrina, PR, Brazil.

[5] Locke, J.C. (1995) Fungi. In Schmutterer, H. Ed., The Neem Tree, VHC. Weinheim, Germany, 118-126.

[6] Bhatnagar, D. and McCormick, S.P. (1988) The inhibitory effect of neem (Azadirachta indica) leaf Extracts on aflatoxin synthesis in Aspergillus parasiticus. Journal of American Oil Chemical Society, 65(7), 1166-1168.

[7] Zeringue, H.J. and Bhatnagar, D. (1994) Effects of neem leaf volatiles on submerged cultures of aflatoxigenic Aspergillus parasiticus. Applied and Environmental Microbiology, 60(10), 3543-3547.

[8] Zeringue, H.J. and Bhatnagar, D. (1990) Inhibition of aflatoxin production in Aspergillus flavus infected cotton bolls after treatment with neem (Azadirachta indica) leaf extracts. Journal of American Oil Chemical Society, 67(4), 215-216.

[9] Allameh, A., Razzaghi-Abyaneh, M., Shams-Gahahfarokhi, M., Rezzar, M.B. and Jaimand, K. (2001) Effects of neem leaf extract on production of aflatoxins and activities of fatty acid synthetase, isocitrate dehydrogenase and glutathione S-transferase in Aspergillus parasiticus. Mycopathologia, 154(2), 79-84.

[10] Razzaghi-Abyaneh, M., Allameh, A., Tiraihi, T., ShamsGhahfarokhi, M. and Ghorbanian, M. (2005) Morphological alterations in toxigenic Aspergillus parasiticus exposed to neem (Azadirachta indica) leaf and seed aqueous extracts. Mycopathologia, 159(4), 565-570.

[11] Mossini, S.A.G., de Oliveira, K.P. and Kemmelmeier, C. (2004) Inhibition of patulin production by Penicillium expansum cultured with neem (Azadirachta indica) leaf extracts. Journal of Basic Microbiology, 44(2), 106-113.

[12] Arrotéia, C.C., Kemmelmeier, C. and Machisnki, Jr., M. (2007) Effect of aqueous and oily extracts of Neem [Azadirachta indica A. Juss (Meliaceae)] on patulin production in apples contaminated with Penicillium expansum. Ciência Rural, 37, 1518-1523.

[13] Mossini, S.A.G. and Kemmelmeier, C. (2008) Inhibition of citrinin production in Penicillium citrinum cultures by neem [Azadirachta indica A. Juss (Meliaceae)]. International Journal of Molecular Science, 9(9), 1676-1684.

[14] Costa, C.L. and Kemmelmeier, C. (2008) Effect of aqueous and oily extracts from Neem [Azadirachta indica A. Juss (Meliaceae)] on the production of mycotoxins by the polyketide pathway (penicillic acid and sterigmatocystin). Current topics in Biotechnology, 4, 3540.

[15] Fandohan, P., Gbenou, J.D., Gnonlonfin, B., Hell, K., Marasas, W.F.O. and Wingfield, M.J. (2004) Effect of essential oils on the growth of Fusarium verticillioides and fumonisin contamination in corn. Journal of Agricultural and Food Chemistry, 52(22), 6824-6829.

[16] Mossini, S.A.G., Arrotéia, C.C. and Kemmelmeier, C.
(2009) Effect of Neem Leaf extract and Neem oil on Penicillium growth, sporulation, morphology and ochratoxin a production. Toxins, 1, 2-13.

[17] Govindachari, T.R., Suresh, G., Gopalakrishnan, G., Banumathy, B. and Masilamani, S. (1998) Identification of antifungal compounds from the seed oil of Azadirachta indica. Phytoparasitica, 26(2), 109-116.

[18] Smith, D. and Onions, A.H.S. (1983) The preservation and maintenance of living fungi. Commonwealth Mycological Institute, Page Bros Ltd., Great Britain.

[19] Betina, V. (1984) Prodution, Isolation, Separation and Purification. In: Betina, V. Ed., Mycotoxins. Elsevier Science Publishers BV, Amsterdam, Netherlands, 183-215.

[20] Davis, N.D., Diener, U.L. and Eldridge, D.W. (1966) Production of aflatoxin B1 and G1 by a Aspergillus flavus in a semi-synthetic medium. Applied Microbiology, 14(3), 378-380.

[21] Farag, R.S., Daw, S.Y. and Abo-Raya, S.H. (1989) Influence of some spice essential oils on Aspergillus parasiticus growth and production of aflatoxins in a synthetic medium. Journal of Food Science, 54, 74-76.

[22] Passone, M.A., Resnik, S.L. and Etcheverry, M.G. (2005) In vitro effect of phenolic antioxidants on germination, growth and aflatoxin B1 accumulation by peanut Aspergillus section Flavi. Journal of Applied Microbiology, 99(3), 682-691.

[23] Sutton L.M. and Starzyk, M.J. (1972) Procedure and analysis of a useful method in determining mycelial dry weights from agar plates. Applied Microbiology, 24(6), 1011-1012.

[24] Bluma, R.V, Etcheverry, M.G. (2008) Application of essential oils in maize grain: Impact on Aspergillus section Flavi growth parameters and aflatoxin accumulation. Food Microbiology, 25(2), 324-334.

[25] López-Malo, A., Alzamora, S.M. and Argaiz, A. (1995) Effect of natural vanilin on germination time and radial growth of moulds in fruit-based agar systems. Food Microbiology, 12, 213-219.

[26] Vargas-Isla, R. and Ishikawa, N.K. (2008) Optimal conditions of in vitro mycelial growth of Lentinus strigosus, an edible mushroom isolated in the Brazilian Amazon. Mycoscience, 49(3), 215-219.

[27] Gusmán-De-Peña, D. and Ruiz-Herrera, J. (1997) Relationship between Aflatoxin Biosynthesis and Sporulation in Aspergillus parasiticus. Fungal Genetics and Biology, 21(2), 198-205.

[28] Bischoff, T.W. and Garraway, M.O. (1985) Ammonium production by races and mating types of Bipolaris maydis and its relationship to mycelium dry weight, sporulation and $\mathrm{pH}$ of the culture medium. Ohio Journal of Science, 85, 155-158.

[29] Marques, R.P., Monteiro, A.C. and Pereira, G.T. (2004) Crescimento, esporulação e viabilidade de fungos entomopatogênicos em meios contendo diferentes concentrações do óleo de Nim (Azadirachta indica). Ciência Rural, 34, 1675-1680.

[30] Deacon, J.W. (2006) Fungal Biology, 4th Edition. Blackwell Publishing, Oxford, UK.

[31] Bankole, S.A. (1997) Effect of essential oils from two Nigerian medicinal plants (Azadirachta indica and Morinda lucida) on growth and aflatoxin B1 production in maize grain by a toxigenic Aspergillus flavus. Letters 
in Applied Microbiology, 24(3), 190-192.

[32] Ghorbanian, M., Razzaghi-Abyaneh, M., Allameh, A., Shams-Ghafarokhi, M. and Qorbani, M. (2008) Study on the effect of neem (Azadirachta indica A. juss) leaf extract on the growth of Aspergillus parasiticus and production of aflatoxin by it at different incubation times. Mycoses, 51(1), 35-39.

[33] Sithisarn, P., Supabphol, R. and Gritsanapan, W. (2005) Antioxidant activity of Siamese neem tree (VP1209). Journal of Ethnopharmacology, 99(1), 109-112.

[34] Gowda, N.K.S., Malathi, V. and Suganthi, R.U. (2004) Effect of some chemical and herbal compounds on growth of Aspergillus parasiticus and aflatoxin production. Animal Feed Science and Technology, 116, 281-291.

[35] Suberu, H. (2004) Preliminary studies of inhibitions in
Aspergillus flavus with extracts of two lichens and Bentex-T fungicide. African Journal of Biotechnology, 3(9), 468-472.

[36] Wilson, D.M., Gueldner, R.C., McKinney, J.K., Lievsay, R.H., Evans, B.D. and Hill, R.A. (1981) Effect of $\beta$-ionone on Aspergillus flavus and Aspergillus parasiticus growth, sporulation, morphology and aflatoxin production. Journal of the American Oil Chemists' Society, 58, A959-A961.

[37] Kale, S.P., Cary J.W., Bhatnagar, D. and Bennet J.W. (1996) Characterization of experimentally induced, nonaflatoxigenic variant strains of Aspergillus parasiticus. Applied and Environmental Microbiology, 62(9), 30753092 . 